Check for updates

Faculty of Nursing, University of Calgary Canada

Correspondence to: jennifer.jackson1@ucalgary.ca Cite this as: BMJ 2021;375:n2589 http://dx.doi.org/10.1136/bmj.n2589 Published: 22 October 2021

\title{
In an age of interprofessional care, why do we need nursing research?
}

Jennifer Jackson assistant professor

"What will you do to support nursing research?” I asked.

"Well, care is interprofessional, so I don't think we really need disciplinary research,” they replied.

This was the first time I had heard this sentiment expressed directly by a physician, but I had brushed up against it before. I was referred to as coming from the "school" of nursing, rather than the faculty. My conference presentations have been greeted with physician jokes of "so that's what nurses do," followed by laughter, or sarcastic questions about how nurses playing sudoku during work time fit into their roles. There are also formalised examples of physicians dismissing nursing. Last year the editor in chief of a medical journal had to apologise ${ }^{1}$ after a peer reviewed article provided comebacks for doctors who were mistaken for nurses. ${ }^{2}$ The idea is out there: that nursing research, and nursing, just does not matter very much.

I would like to address these misconceptions. Firstly, we do not truly have interprofessional care unless we have professions. To have professions, we need to have a discrete body of disciplinary knowledge that we create and apply in practice. ${ }^{3}$ Otherwise, we are workers applying someone else's expertise. Many professions work in our healthcare systems, and their ongoing professionalisation and self-regulation relies on each group having disciplinary research.

Secondly, there in an inherent assumption that in interprofessional teams, physicians are the team leaders. Consequently, medical research is what really matters. We would benefit from recognising and addressing how medical work is privileged, and how this ranking can neglect healthcare outcomes that are important to patients. Patients can experience symptoms or side effects that have a huge impact on their quality of life, but which are outside the realm of medicine. For example, alopecia after critical illness is a low ranked concern for physicians, but one of the most distressing outcomes for patients. ${ }^{4}$ Nurses are well placed to support patients with alopecia, which can make a substantial difference for those patients and their families.

Thirdly, the idea that nursing research is inferior to medical or team research reflects a long history of subordination. ${ }^{5}$ Some healthcare professionals are starting to acknowledge this legacy, along with its complex web of class, race, and sex discrimination. However, you don't need to look far to see how the support structures that reinforce the superiority of medical research still exist. Nurses make up $60 \%$ of healthcare professionals in almost every healthcare system in the world, compared with the approximately $10 \%$ of professionals who are physicians. $^{67}$ Yet whether we look at funding for nursing research, the impact factors of nursing journals, or the prevalence of nursing scholarships, it is not hard to see that professional structures in medicine rank higher. Nurses spend the largest proportion of their time with patients of any healthcare professional, ${ }^{8}$ and to improve patient care, we need to support the people who spend the most time at the bedside.

I focus on nursing here, but these lessons apply broadly. Whether it be social workers, speech and language pathologists, audiologists, or other professionals, everyone contributes. The idea that those contributions and the body of knowledge they rest upon can be subsumed into "interprofessional teams" neglects the relative power and privilege that is inherent in all healthcare settings. It also diminishes the expertise that each profession adds to our patients' care.

During covid-19, it has become desperately clear that all healthcare professionals are essential. Our systems have seen a time of rapid change, and a mutual recognition that there is no "going back" when the pandemic is over. In a renewed sense of solidarity, I call on readers to appreciate the value of disciplinary research and recognise its impact on patient care. Nursing research deserves to be properly funded, published, and respected. We have a lot of problems we need to work on in our healthcare system. Valuing each other's research is a good place to start.

Competing interests: none declared. Laupacis A. Apology from CMA/s editor-in-chief. CMA/2020;192:E321-21. doi: 10.1503/cmaj.74914. pmid: 32392517

2 Manzoor F, Redelmeier DA. Sexism in medical care: "Nurse, can you get me another blanket?". CMA/2020;192:E119-20. doi: 10.1503/cmaj.191181. pmid: 32015082

3 Parse RR. Nursing: the discipline and the profession. Nurs Sci $Q$ 1999;12:275-6. doi: 10.1177/089431849901200401. pmid: 11847628

4 Battle CE, Lynch C, Thorpe C, etal. Incidence and risk factors for alopecia in survivors of critical illness: A multi-centre observational study. J Crit Care 2019;50:31-5. doi: 10.1016/j.jcrc.2018.11.015. pmid: 30471558

5 Wuest J. Professionalism and the evolution of nursing as a discipline: a feminist perspective. J Prof Nurs 1994:10:357-67. doi: 10.1016/8755-7223(94)90039-6. pmid: 7822625

6 World Health Organization. Gender equity in the health workforce: Analysis of 104 countries. World Health Organization, 2019: 8.

7 World Health Organization. State of the world's nursing: Investing in education, jobs and leadership. World Health Organization, 2020.

8 Bridges J, Nicholson C, Maben J, etal. Capacity for care: meta-ethnography of acute care nurses' experiences of the nurse-patient relationship. J Adv Nurs 2013:69:760-72. doi: 10.1111/jan.12050. pmid: 23163719 